\title{
Teorías, Actores y Redes de la Ayahuasca
}

\author{
Oscar Calavia Sáez
}

Universidade Federal de Santa Catarina, SC, Brasil

E-mail:occs@uol.com.br 


\section{Resumo}

O uso da ayahuasca, mesmo no seu espaço indígena original, não pode ser descrito como um corpo, culturalmente variável, mas culturalmente circunscrito, de conhecimentos tradicionais, rituais ou técnicas xamánicas. Este artigo o descreve, antes, do mesmo modo em que são descritas a ciência e a técnica modernas, como uma rede de atores humanos e não humanos (espíritos, substâncias bioquímicas, especialistas, clientes, teorias sobre os seus princípios e objetivos) transformando-o à medida que o executa e o dissemina. O artigo tenta ser um survey da diversidade de composições, usos e agentes da ayahuasca na Amazônia indígena

Palavras-chave:Ayahuasca. Xamanismo. Teoría ator-rede. Índios da Amazônia.
Abstract

The use of ayahuasca, even in its original indigenous ground, cannot be described as a culturally variable but culturally bounded body of traditional knowledge, ritual or shamanic technic. This paper describes it rather in the way in which modern science and technology are described, as a network of human and non human actors (spirits, bio-chemical substances, specialists, clients, theories on its principles and goals) that transform it as long as they perform and disseminate it. The paper is a tentative survey on the diversity of composition, uses and agents of ayahuasca throughout the Amazon.

Keywords: Ayahuasca. Shamanism. Actor-network theory. Amazonian indians. 


\section{Introdução}

T a referencia nada discreta a Latour (2007) en el título de este Lartículo no es un contrato por el que el autor se comprometa a inscribir su descripción en las tramas de la actor-network theory. Más bien, supone que la ayahuasca lo hará por sí misma, o mejor aún, que acogerá en su seno, muy a gusto, esa innovación metodológica. Porque conozco pocos temas donde la proliferación de controversias, el reconocimiento de actores no humanos, o la creatividad de mediador nunca reducidos a intermediarios se muestren con más brío que en este campo en que algunos - actores cogidos sin saberlo en la misma red - aún pueden ver una tradición milenariamente fija. Esa encarnación de motivos más corrientemente señalados en campos como los estudios de ciencia y tecnología se hace más conspicua porque este estudio se dedica exclusivamente - aunque sin ignorar sus híbridos - a la ayahuasca en el ambiente indígena ${ }^{1}$.

Sería difícil, y no es esa mi pretensión, hacer un inventario de lo que ya se ha escrito a respecto de la ayahuasca indígena. Pocas monografías sobre los índios de la Alta Amazonia dejan de dedicar algunas páginas - en general, dentro del capítulo dedicado al chamanismo al uso de la banisteriopsis caapi. Estas informaciones permanecen, en general, aisladas. La etnología amazónica es un campo de estudios bien acondicionado, dotado de síntesis, grandes teorías, bibliografías críticas y una densa red de referencias internas. Pero toda esa organización sigue líneas clásicas como las de la mitología, el parentesco o el chamanismo: raramente ha seguido los caminos ofrecidos por la liana. No se ha insistido lo suficiente en lo que, por un motivo familiar a los difusionistas, constituiría el principal interés de la ayahuasca 
indígena: en su centro declarado de origen, la ayahuasca muestra una complejidad mucho mayor que en los lugares para donde se habría extendido con posterioridad (Bianchi, 2005). Es precisamente esa complejidad la que intentamos sencillamente indicar en este esbozo.

\section{Una Red de Sustancias}

Como se sabe, la ayahuasca es una poción habitualmente compuesta por dos estancias diferentes, la liana banisteriopsis y la hoja de la psychotria, aunque la poción en si sea identificada con la liana, y designada - en portugués y en español, pero también en las lenguas de los pueblos indígenas que la utilizan - con el nombre que corresponde a ella ${ }^{2}$. Como indica Deshayes (2003), esa identificación es paradójica, ya que el poder visionario de la poción reside precisamente en el ingrediente no marcado, la psychotria, limitándose la acción de la banisteriopsis, en lo que toca a visiones, a evitar que el principio activo de la psychotria sea neutralizado por las enzimas del estómago. En el artículo de Deshayes, esa cuestión léxica sirve para introducir un contraste entre los usos nativos y urbanos de la ayahuasca: fuera de la selva, una larga tradición cristiana y platónica habría conducido la imagen y la visión al centro de la experiencia de la ayahuasca. En la selva, esa potencia eidética, contribución de la psychotria, estaría al servicio de otra eficiencia, la propia de la liana, que actúa en el cuerpo digamos visceral de sus bebedores. No por azar términos como "purga" o "dieta" (los Matsiguenga llaman a la ayahuasca kamarampi, "la que hace vomitar", conforme Shepard, 2005, p. 201) son comunes entre curanderos indígenas y mestizos, sobre todo en la Amazonia peruana, para designar el uso de la poción. El artículo de Deshayes - aunque discorde de alguno de sus puntos principales, especialmente en lo que se refiere al valor de la visión en la ayahuasca indígena - abre discusiones valiosas sobre la relación entre la farmacología y la etnología de la ayahuasca.

La ayahuasca, resultado de la interacción - que no de la suma simple - de dos fármacos, es tal vez la mejor demostración de la profundidad, la eficacia y la extensión de la ciencia indígena; aun más si consideramos que esa composición se diversifica por el empleo de 
diversas variedades, silvestres o cultivadas ${ }^{3}$. Los Aguaruna usan (o usaban, Brown, 1985, p. 58) dos variedades de liana; los Sibundoy (Ramírez de Jara; Castaño, 1992, p. 290) tres; los Matsiguenga (Shepard, 2005, p. 201) cinco; y los Siona (Langdon, 2005, p. 17) mas de dieciséis. Los Kaxinawá (Lagrou, 2000, p. 35 ) hablan de cuatro variedades de la sustancia: blanca, azul, roja y negra, cada una de ellas una parte del cuerpo de Yube (la anaconda mítica que encarna la liana), con propiedades diferentes, siendo que las coloridas propician bellas visiones y la blanca y la negra están relacionadas con efectos maléficos. Un mito Desana (Reichel Dolmatoff, 1975, p. 134-136) remite el origen de la ayahuasca al desmembramiento de un niño cuyo largo cordón umbilical prefigura la liana; cada variedad procede de una parte de ese cuerpo y corresponde a uno de los pueblos que proceden del viaje de la anaconda primordial en el mito Desana. Pero en la preparación factual de la bebida tienen también espacio los diversos estados de la liana, recogida en distintos grados de maduración, cortada a diferentes alturas, etc. (Reichel Dolmatoff, 1975, p. 155). Hay variación también, aunque menor, en el uso de la Psychotria, a veces sustituida por diplopterys o datura o acompañada por un número difícil de definir de aditivos (Ramírez de Jara; Castaño, 1992, p. 290-291; Luna, 2005, p. 335). Todo ese detalle no prolifera a ciegas. En una sesión de ayahuasca en la que participé, en 1998, en la aldea yawanawa del río Gregorio, el chamán encargado de elaborar la poción enunció con precisión las propiedades que había propiciado y evitado con su fórmula (en el caso, un efecto rápido, y la minimización de vómitos o diarreas inconvenientes para una sesión muy concurrida). La ayahuasca es el centro de una experimentación extensiva con la flora local, que por lo demás no está en absoluto cerrada a la posibilidad de ensayos con sustancias exógenas.

Toda esa diversidad no es fácil de cartografiar. De inicio, por razones taxonómicas: la fitodiversidad amazónica está lejos de encontrarse catalogada, y presenta dificultades especiales por causa, precisamente, de su densidad; los criterios usados por los nativos para la clasificación de la liana, por lo demás, no coinciden necesariamente con los que son relevantes para los botánicos, lo que complica aun más esa clasi- 
ficación (Luna, 2005, p. 335). Pero, también, por razones políticas: el conocimiento nativo amazónico es un campo abierto a los abusos y las especulaciones: hechos como la patente, registrada hace ya años por la empresa Selva Viva, de una variedad de liana recolectada en una chacra indígena ecuatoriana, crean olas de desconfianza a respecto de las investigaciones etnobotánicas o etnofarmacológicas. Esas olas se deben no solo a la amenaza de un biocolonialismo global, sino también a las restricciones privadas que se oponen a la circulación de un conocimiento que es patrimonio de chamanes individuales, y como tal objeto de una red de intercambios de alto valor. (Calavia Sáez; Carid Naveira; Pérez Gil, 2003)

La analogía científica tiende a hacer del chamanismo una forma de investigación, lo que quizás sea su traducción menos injusta; pero es preciso notar que ella está en las antípodas de una experimentación con "principios activos", dirigida al aislamiento y la determinación de sus propiedades en un contexto controlado - incluso si este control se reduce al ayuno frecuentemente prescrito en los laboratorios de la selva. El uso indígena de la ayahuasca se dirige, precisamente, a poner en relación una serie de agentes - incluyendo sustancias alucinógenas, embriagantes o curativas - entendidas como sujetos, no como materias con propiedades. La orientación moral de la ayahuasca, es decir su uso curativo o agresivo, depende mucho menos de las inclinaciones del practicante, y de su grado de respeto a las buenas normas, que de la voluntad de las propias plantas (Freedman, 2000, p.113). En la que tal vez sea la más antigua descripción de su uso (Spruce, 2000) ${ }^{4}$, la ayahuasca se acompaña con grandes cantidades de caxiri (un fermentado de mandioca), vino de palma y tabaco. En las descripciones del ritual de Reichel-Dolmatoff (1975) forman parte del ritual el caxiri, el tabaco (compañero casi inseparable de la ayahuasca, y agente chamánico mucho más común que esta) y el polvo de viho (Reichel-Dolmatoff, 1975, p. 155-167). Pero debemos ampliar la lista considerando, no solo las sustancias que acompañan el consumo de ayahuasca, sino también las que se alternan con ella en la práctica chamánica. Los Aguaruna (Brown, 1985, p. 58) utilizan, además de la ayahuasca, tabaco y tres tipos de datura, a los cuales algunos practicantes añaden piripiri 
(cyperus) y jengibre. La descripción más detallada de estos conjuntos chamánicos es la de Chaumeil (1983), especialmente al transcribir el proceso de iniciación relatado por uno de sus principales informantes, Alberto Prohaño. Las sustancias ingeridas por el chamán yagua durante su proceso de iniciación constituyen un conjunto abierto, que comienza con la ingestión de piripiri (cyperus), seguida por la mezcla de piripiri y zumo de tabaco (que después será sustituido, en la practica chamánica, por su humo); con la adición en una tercera fase de ayahuasca, de toé (datura) en la cuarta, y finalmente de vegetales o sustancias más poderosas, como el naranjillo, el venado-caspi, la gasolina, el querosén y el alcanfor (Chaumeil, 1983, p. 33-43). Cada una de esas etapas acumulativas supone el encuentro con los espíritus de esas sustancias, y una negociación más o menos ardua y peligrosa con ellos. Los relatos a respecto del chamanismo Pano (para el caso Shipibo; Roe, 1982, p. 123-126) citan también un conjunto de sustancias, incluyendo, más allá de la ayahuasca y el toé, la savia de la samauma, conocida como yowi, dotada de poderes maléficos y que probablemente en el pasado desempeñó un papel mucho más conspicuo. La lista, desde luego, no acaba ahí: un informante de Gebhart-Sayer (2000) añade, por ejemplo, shahuan-peco, una planta parasita no identificada que antiguamente era usada en el chamanismo shipibo como alucinógeno, en lugar de la ayahuasca o sumada a ella; Abreu (1941, p. 172-175), que no alude nunca al uso de ayahuasca en la investigación realizada con dos jóvenes Kaxinawa en inicio del siglo XX, recoge un relato detallado del uso de xumá, una decocción "muy venenosa" de corteza de samauma y palmitos y frutos de una serie de palmeras - paxiuba, uricuri, pataua, jarina - que ponen a quien la bebe en contacto con las almas, quienes la favorecerán con todo tipo de regalos y con una pesca afortunada. Yo mismo oí de los Yawanawa una exposición muy organizada de la lógica de esos conjuntos: ayahuasca, datura, tabaco y chile forman la panoplia básica del chamán, en funciones muy específicas. El chile es un arma agresiva, procesada por el cuerpo del chaman en forma de sudor, que puede ser enviado contra los enemigos por medio del soplo. El tabaco es por el contrario el escudo necesario en sus interacciones con los espíritus; en el proceso iniciatorio descrito por Chaumeil 
(1983), el chamán Yagua usa el tabaco precisamente como un regalo conciliador destinado a los espíritus con los que se depara ${ }^{5}$. La datura es el tercer y más potente de los agentes: en la descripción yawanawa, produce visiones asociadas a la guerra, pudiendo prever su desenlace (y por tanto desencadenarla). La ayahuasca, en fin, aparece en ese conjunto como un instrumento de diagnostico, o como un traductor universal, que permite un amplio tránsito por el otro mundo: como reza un comentario del mito Desana anotado por Reichel Dolmatoff (1975, p. 136), "mankind needed a means of communication; it was for this reason that the Sun Father was searching for Yaje". El uso de la ayahuasca permite a los iniciados descubrir todas las medicinas, anotadas en un libro guardado en la Casa de Dios (Langdon, p. 47) o encontrarse con los espíritus maléficos y combatirlos (Illius, p. 66).

Un panorama de la practica actual del chamanismo alto-amazónico nos presenta la ayahuasca como principal, o única heredera de una gama de sustancias psicoactivas que, a poco que examinemos descripciones de momentos más antiguos de ese mismo chamanismo - o del chamanismo de pueblos indígenas más apartados - se muestra mucho más variada: prueba de que, lejos de ser algo así como una tradición fielmente conservada, el chamanismo amazónico es un saber en rápida mutación. Es difícil saber cómo las cualidades peculiares de la ayahuasca pueden haber contribuido a esa elección. Este artículo es un survey incompleto de trabajos etnográficos que cuenta, en el mejor de los casos, con un ligero barniz de información botánica y farmacológica; el objetivo es mucho más indicar la amplitud de una variación que describirla en detalle o explicar sus líneas generales. Con mejores informaciones sobre los efectos de otras drogas comunes en el chamanismo amerindio (que, a diferencia de la ayahuasca, raramente han sido probadas por los etnógrafos), podríamos quizás saber algo más sobre los motivos que la han llevado a sustituir otras sustancias o para actuar entre ellas como una especie de agente-eje - nunca el más poderoso, pero si el mas capaz de articular los otros. Podríamos recurrir a la tesis de Furst (1990) de que, abandonando plantas más peligrosas o menos previsibles, los sistemas chamánicos se habrían ido decantando, en épocas recientes, por agentes de uso más confiable, como el peyote 
en el caso de que él se ocupa, o de la ayahuasca en el nuestro, siempre rodeada de agentes más poderosos pero ya marginados o en desuso. Quizás, para el caso sudamericano, sea revelador fijarse en ese código culinario que, a partir del modelo levi-straussiano, Peter Roe (1982) aplica a las plantas de poder Shipibo: frente a la datura y al yowi crudos, ligados al maleficio, la ayahuasca, cocida y auxiliar de las buenas obras del chaman, remite al polo simbólico de la socialidad y la civilización. Ese código culinario no está rigurosamente definido: ya hemos visto cómo, en ausencia de ayahuasca, la corteza de samauma (de donde procede también el yowi) puede usarse cocida, y la ayahuasca puede usarse cruda. La ayahuasca se obtiene de plantas silvestres o cultivadas, siendo que a veces (Gow, 1996, p. 105) se expresa una preferencia por aquella que, cultivada en chacras ya abandonadas - en cierto sentido, asilvestrada - se sitúa a medio camino entre el poblado y la selva, o en la divisorias entre cualquiera otra polaridad ${ }^{6}$. La aproximación que el propio Gow (conforme más adelante) sugiere entre la ayahuasca y la figura del mestizo parece casar con una identidad mediadora más general. Comparando sus efectos con los mas raramente descritos de los otros psicoactivos chamánicos comunes, la ayahuasca se diferencia de esos agentes, más peligrosos, que proporcionan experiencias propiamente extáticas, con pérdida o alteración de la conciencia común, a veces durante largo tiempo; pero se diferencia también de aquellos otros que, como el tabaco y el cyperus, se toman a veces como auxiliares en actividades como la caza. El usuario de ayahuasca solamente ve o danza, apartado de las actividades corrientes; pero no se ve lanzado a otro mundo. Está lo bastante lejos para entrar en contacto con espíritus sin por ello renunciar a la comunicación con los humanos. La paradoja enunciada por Deshayes (2000) se resuelve si consideramos que la "producción" de imágenes que reconocemos como virtud de la psychiotria no cuenta como tal en la opinión indígena: las imágenes ya están ahí de cualquier modo, y lo que se necesita es un agente que abra el camino que lleva a ellas, la liana en el caso. Es sugestivo comprobar que, aunque un gran número de sustancias vegetales sean usadas en Sudamérica por su potencia visionaria, en el caso de la ayahuasca esa visión es con una especial frecuencia asimilada a una escritura, a un 
código presente en las visiones, en las pieles de los animales de la selva (especialmente el jaguar y la anaconda), o en los "libros" en que los espíritus guardan los secretos de la selva. La escritura, actividad solitaria - y, en el contexto amazónico, extraordinaria - que entretanto es capaz de servir a la comunicación, puede ser un buen equivalente de esa sustancia cuya característica más notable puede ser su virtud de permanecer en el punto medio de las relaciones y las clasificaciones.

En fin, es importante destacar que la farmacología amazónica conducida por esos experimentadores incansables, los chamanes ${ }^{7}-\mathrm{es}$ una obra abierta. Abierta porque va renovándose constantemente, sin haber fijado definitivamente los valores de sus elementos (crudo o cocido, cultivado o no, etc.); pero abierta también porque no procede aislando sustancias y profundizando en sus propiedades diferenciales, sino promoviendo lo que no podría ser descrito mejor que como un diálogo entre los diversos sujetos del universo.

\section{Una Red de Eficacias}

La ayahuasca desempeña en las religiones ayahuasqueras o en las elaboraciones new age un papel terapéutico, y esa caracterización suele ser extendida automáticamente a los usos indígenas. Contribuye a ello una tendencia corriente a ver el chamanismo como una especie de medicina, evitando los aspectos de este que puedan reforzar estereotipos negativos sobre el propio chamanismo, o sobre los índios que lo practican. En la medida en que los propios chamanes se han ido destacando como representantes del mundo indígena en el escenario nacional o global, el chamanismo ha sido sometido a un proceso de moralización y de vegetalizacion, presentándose como una especie de terapia naturalista, que se limita a teñir de mística primitivista el uso universalmente extendido de las plantas medicinales. Se trata, claro está, de una reelaboración reciente que no hace justicia a la complejidad del chamanismo indígena, ni del propio uso de la ayahuasca.

La diversidad de ese uso puede empezar por el modo en que la sustancia es aplicada. Aunque hayamos aludido constantemente a una poción o brebaje, vale la pena recordar que esa no es su única preparación, y que por tanto los modos de entender su eficiencia no se limitan 
a los efectos de la bebida. En vísperas de una sesión de ayahuasca realizada en la aldea, encontré a un viejo Yaminawa dándose friegas en el pecho con el bagazo de la liana usada en la preparación; contaba con eso obtener un complemento de los beneficios que esperaba de la sesión. Aunque el cipó se tome regularmente cocido, no faltan ejemplos de su extracción en frío (Luna, 2005, p. 335). Los índios del Orinoco, según Spruce (2000, p. 85) "not only drink the infusion, like those of the Uaupés, but also chew the dried stem, as some people do tobacco". De nuevo Furst, (1990, p. 54) aludiendo a fuentes etnohistóricas no especificadas, sugiere el uso de ayahuasca (y de otros psicoactivos, sobre todo el tabaco) en forma de enema. El mito Huaorani de origen de la ayahuasca presenta la presenta como un facilitador de la caza y, en una analogía que se le ocurre al mismo protagonistas del mito, como facilitador, también de mujeres (Miller-Weissberger, 2000) ${ }^{8}$. En el mito, la ayahuasca actúa principalmente a través de su fragancia, adentrándose así en el universo de los fármacos no destinados a enfermedades, y en particular en el de los perfumes, un universo que, como puede apreciarse en el estudio de Leclerc (2004) sobre los noi rao Shipibo nada tiene de inocente. No solo porque la caza ya sea en si una metáfora de la guerra, sino porque el uso erótico (que no deja de ser un tipo de caza) remite a la causa más comúnmente invocada de conflicto. Los Yaminawa, que continúan, con las restricciones que indicaré más tarde, la práctica de la ayahuasca, son taxativos en cuanto a su condena de los perfumes, cuyo uso fue prohibido hace tiempos, según dicen, por la inestabilidad que esa manipulación erótica solía causar.

La ayahuasca, sobre todo en las descripciones de su uso en los tiempos antiguos - menos vulnerables a las censuras ajenas - presenta un valor mucho más siniestro que el que la new age indianista le atribuye. Es, obviamente, un agente de esa hechicería cuya doble cara se hace tan presente en el chamanismo ayahuasquero como en cualquier práctica análoga en cualquier continente, y basta consultar las obras aquí reseñadas para entrar en sus detalles. Pero la ayahuasca aparece también, y muy especialmente, como catalizador de la guerra profana. Ya en la descripción de Spruce (2000), el primer efecto del brebaje era una reacción agresiva del usuario: este se alza y toma la primera arma 
que encuentra a mano, atacando a un enemigo virtual. Según relatos yaminawa, la ayahuasca propiciaba otrora encuentros entre grupos próximos, que se entregaban juntos a las visiones y competían mostrando su conocimiento de los cantos. Pero esos conclaves envolvían un peligro manifiesto: el de transformarse en enfrentamientos súbitos y letales - de hecho, episodios de ese tipo son la explicación común de las guerras del pasado antes de la vida entre los blancos. Un pasado que debe ser cualificado: tales relatos no remiten al "tiempo de los antiguos", sino a la muerte de algún pariente próximo, o a las cicatrices aun visibles en la cabeza de algún hombre maduro. La ayahuasca ejercía una especie de diplomacia negativa propiciando visiones en que los compañeros de fiesta se revelaban como enemigos.

El misionero dominico Ricardo Álvarez (1984) narra uno de esos episodios, en que los Yaminawa exterminan a un grupo de Amahuaca recién llegado a la misión en que ellos mismos estaban instalados, después de haber visto por medio de la ayahuasca los planes equivalentes que los Amahuaca ultimaban a su respecto. Véase que en este caso la ayahuasca actúa en el mismo sentido en que la datura lo hace en el paradigma Yawanawa antes descrito: haciendo ver guerras del futuro que pueden ser venidas, y adelantándolas como guerras preventivas. En una variante de ese mismo uso, la ayahuasca ejercía como vehículo por medio del cual los muertos comparecían para exigir a sus parientes vivos que los vengasen de sus matadores; la propia sangre del deudo muerto podía mezclarse al brebaje para propiciar esas manifestaciones ${ }^{9}$.

Esa misma potencia adivinatoria pode haberse usado para fines más consensuales. Según Spruce (2000), los nativos de los ríos Napo y Bombonaza toman la ayahuasca como "a narcotic stimulant at their feasts" pero también como un instrumento del

[...] medicine-man, when called on to adjudicate in a dispute or quarrel - to give the proper answer to an embassy - to discover the plans of an enemy - to tell if stranger are coming - to ascertain if wives are unfaithful - in the case of a sick man to tell who has bewitched him, etc. (Spruce, 2000, p. 85)

Al margen de todos esos usos, en buena parte datados en épocas más o menos distantes, encontramos, desde luego, lo que podríamos 
llamar la versión canónica del uso del brebaje, es decir, como agente de procesos terapéuticos, como sustancia poderosa que se sedimenta en el cuerpo del chaman - junto con otras sustancias en general amargas a veces en forma de flechitas o flemas - y como facilitador de visiones de naturaleza muy diferente. En el caso Siona (Langdon, 2000) los efectos de la ayahuasca se desdoblan en tres fases: primero, una ebriedad sin significado, después una ola de visiones tenebrosas que pueden incluir "frightening snakes, fires, black monsters and grinding machines" que amenazan la misma existencia del bebedor. En fin, si este es capaz de superar la prueba, una nueva vision aparece, "full of light, and the yage people descends to show the novice the way". Una secuencia parecida es descrita por ejemplo entre los Sharanahua (Siskind, 1973, p. 168), donde la fase agónica es protagonizada por anacondas que enlazan y aprietan el cuerpo del enfermo hasta casi asfixiarlo. El hombre "se siente morir, pero no muere; está curado" como me explicaban los Yaminawa del Río Acre. Esa pseudo-muerte del visionario es una descripción muy extendida del proceso de cura por la ayahuasca, y sugeriría una analogía con una especie de abreacción psicoanalítica. Debemos tener precauciones también con esa nueva analogía. Primero, porque la experiencia en si es una escenificación de la mitología - el mito del hombre que tomo conocimiento de la ayahuasca debajo de las aguas - y permitiría lecturas "perspectivistas" (la muerte a manos de las serpientes en el otro mundo equivale a la vida en este) muy distantes de racionalizaciones psicológicas. Segundo, porque la cura por la ayahuasca no, necesariamente, pasa por una experiencia del enfermo. A veces, él ni siquiera toma la bebida, y lo más común es que la experiencia central del proceso de cura sea la del chamán y no la de su paciente. Es el caso de una de las terapias mejor narradas, la de la cura Shipibo por dibujos descrita por Gebhart Sayer (2000), a la que se aludirá más tarde.

No pretendo entrar aquí en el detalle de las curas o de las agresiones que la ayahuasca propicia; eso sería, en rigor, discutir no la ayahuasca sino el chamanismo, que mantiene con ella una relación privilegiada sin, no obstante, identificarse con ella.

El punto es problemático. La función más extendida de la ayahuasca, sintetizando mucho, viene a ser algo así como una prope- 
déutica general que, actuando sobre el cuerpo o más específicamente sobre la visión de su usuario, lo torna más apto para algún tipo de comunicación, sea esta comunicación la del chamán, la del guerrero, la del cazador, la del seductor. Eso incluye algo muy próximo a lo que suele llamarse uso "recreativo". Efectivamente, cuando se pregunta a los usuarios Yaminawa para que toman ayahuasca, la respuesta más común - casi me atrevo a decir que sería la misma en toda la Alta Amazonia - es que la toman simplemente para ver, y esta respuesta viene acompañada por una serie de analogías con técnicas occidentales que también sirven para la recreación y para la obtención de informaciones: el cine, la televisión y el video (y a estas alturas probablemente la internet).

A comienzo de los años noventa, cuando se extendía por la frontera con Perú el temor de la epidemia de cólera que se había desatado en aquel país, recuerdo haber oído hablar en el Acre de un sobrevuelo en helicóptero que algunas autoridades de la región habían hecho para comprobar el avance de la epidemia. A falta de más detalles sobre esa expedición, no sé hasta qué punto se asemejó a la que el chamán Yaminawa, mucho más económico, realizó con la ayuda de la ayahuasca, comprobando que la epidemia se encontraba aún en Santa Rosa, en el Perú. Sin motivos tan graves, la ayahuasca permite a otros conocer lugares inalcanzables, explorar la ciudad próxima a la que piensan ir físicamente en breve, o simplemente contemplar con una precisión imposible para el ojo el mundo magnifico de la selva vecina. Eso ¿es, o no es chamanismo? Tal vez el desacuerdo sobre si los chamanes Kulina usan (Viveiros de Castro, 1978) o no usan (Pollock, 1992, p. 39) la ayahuasca se deba en parte a una discordancia sobre la extensión del chamanismo - ora una especialidad mágica o terapéutica, ora una visión del mundo o de los modos posibles de conocerlo. La idea de un chamanismo generalizado no es monopolio del área de utilización de la ayahuasca, pero sin duda ella le proporciona una expresión muy clara en la Alta Amazonia. 


\section{Actores humanos}

El misionero y etnógrafo Constantin Tastevin (Tastevin, 1925, p. 414) recogía una información Kaxinawa que atribuía a los Yaminawa la invención de los dos mayores ítenes de la farmacología indígena: la ayahuasca y el veneno de sapo. Esa atribución se debía probablemente al carácter "salvaje" que ellos consideraban propio de los Yaminawa, tan reticentes a la comunicación con otros pueblos como íntimos de la selva. En general, ese mismo estereotipo define lo que, desde el universo urbano, se piensa a respecto de la ayahuasca indígena: una práctica creada en un contexto de autoctonia, aislamiento e inmersión en el medio ambiente. La ayahuasca seria el sacramento de un chamanismo incluido o recluido en los límites de un pueblo y de una cultura, y, desde luego, un sacramento milenario. Pero un vistazo un poco más atento desborda ese esquema por sus dos extremos, haciendo de la ayahuasca indígena algo mucho más amplio, algo mucho más restringido y tal vez no tan viejo.

Rituales como los descritos por Reichel-Dolmatoff ( 1975) o Hugh Jones (1996) para el conjunto Tukano han quedado, por meritos propios, como modelo del uso indígena de la ayahuasca. Ocasiones colectivas, bien reguladas, con cantos y danzas en una secuencia prevista y controlada por especialistas, que ofrecen una excelente metáfora de la sociedad entendida en un sentido durkheimiano. Buenos ejemplos, también, de lo que Hugh Jones (1996) llamó chamanismo vertical, donde el especialista, muy próximo de lo que llamaríamos un sacerdote, administra la poción a otros para que conozcan personalmente el mundo que el chamán frecuenta. Rituales semejantes pueden encontrarse en toda la región. La ayahuasca "de danzar" de los Baniwa (Wright, 2005, p. 93) tiene un valor festivo que ocupó el lugar de un viejo ritual de preparación para la guerra. El saiti de los Yawanawa, que también recurre a la ayahuasca, presenta un valor paralelo, y, recuperado después de un largo periodo de abandono, pasa a representar el modelo de un ritual indígena genérico - el mariri acreano, equivalente en ese carácter genérico al dabucuri del noroeste amazónico.

Vale la pena notar que en ambos casos la ayahuasca ocupa en el ritual el mismo lugar que, fuera del área de la ayahuasca, ocupan las 
bebidas fermentadas (que en la descripción de Spruce (2000), dividían la escena con el yagé) u otras sustancias psicoactivas, como la Jurema de los torés de los indios nordestinos - un caso más de ritual genérico (Mota, 2005). En el contexto del culturalismo indígena de los últimos decenios, la ayahuasca ha pasado en ocasiones a representar, tout court, la cultura indígena. (Weber, 2006, p.149)

Pero ese uso ceremonial y colectivo es, en la actualidad, minoritario, a pesar de la proliferación de rituales "recuperados". En la mayor parte de las descripciones, la toma de ayahuasca sigue un protocolo que difícilmente podría incluirse dentro del término "ritual", a no ser en acepciones extremamente latas. En general, se trata de sesiones que reúnen en un espacio privado (la casa del chaman o algún alojamiento aislado destinado a ese fin) a los interesados en un proceso de cura, o de iniciación, o simplemente en ver lo que la ayahuasca quiera mostrarles. Robinson (2000, p. 96) explica que el chaman que dirigió las sesiones de ayahuasca en que él tomó parte

[...] never would address the group and offer any prologue, profecy or rethorical menu for the evening's visions and proceedings. Occasionally, his helper or a visiting Kofan would chant whith him, late, in the wee hours before dawn. He was in charge of his own access to the yagé people, and catalysed, as best he could, what the rest of us were seeing. This was an intensively collective and private affair, and whence its therapeutic virtues.

Fueron así, también, casi todas la sesiones a que me fue dado asistir entre los Yaminawa y los Yawanawa, y ese mismo esquema puede encontrarse en toda la Amazonia, coincidiendo con el modelo del chamanismo horizontal de Hugh-Jones (1996). La ayahuasca sirve predominantemente a una actividad privada, cuyos requisitos se aproximan más de una maestría técnica que de un ritual, y son muy variables las relaciones entre esa práctica discreta y su eclosión en forma de fiesta colectiva. Si el yagé preside - o presidía - las ceremonias colectivas Desana, está por el contrario singularmente ausente en las actividades de los diversos tipos de chamán Desana, que sin embargo utilizan una rica parafernalia de otras plantas psicoactivas (Buchillet, 1992, p. 211-230) ${ }^{10}$. Los Sharanahua utilizan la ayahuasca 
en sesiones restringidas, mientras celebran, sin su contribución, los mismos segmentos festivos que componen el mariri de los Yawanawa, o las antiguas fiestas Yaminawa. Lo más común ha sido el progresivo abandono del uso colectivo, mientras permanecía o incluso se extendía el uso privado. Un buen ejemplo es el de los Yaminawa: en mi propio trabajo de campo oí hablar constantemente de un uso colectivo y festivo, semejante al del mariri, que incluía, no hace muchos años, hombres y mujeres ${ }^{11}$; y Pérez Gil (2004), tratando de los Yaminawa peruanos, relata para un pasado también no muy distante la práctica de una iniciación chamánica colectiva - restringida a los hombres ahora ya abandonada.

Esa disgregación de los antiguos ritos colectivos puede ser incluida en la cuenta de la represión cultural ejercida durante largos años por misioneros o agencias laicas - una censura no limitada a rituales de este tipo, aunque el uso de psicoactivos le haya servido de estimulo - o entendida por el aflojamiento de los lazos internos de pueblos sometidos a un proceso colonial. Pero a veces se presenta como una iniciativa indígena dentro del contexto de la pax branca: los rituales de ayahuasca pueden ser demasiado peligrosos en situaciones donde la guerra ya no puede formar parte de la vida común. Se da, así, si no el simple abandono de la práctica, un proceso de especialización del uso de la ayahuasca, del cual puede dar una buena idea el chamanismo Yaminawa, antes generalizado y actualmente reservado a poquísimos conocedores, mutilado - al menos nominalmente - de sus expresiones máximas y más peligrosas, y condicionado a un proceso voluntario e individual de iniciación, extremamente duro en términos físicos y económicos.

Y sin embargo esa restricción histórica puede significar por otro lado una ampliación, en la medida en que la circulación individual de los usuarios, que probablemente ya tenía antes grandes proporciones, se intensifica y alcanza mayores distancias. Lejos de ser parte de un substrato autóctono, la ayahuasca es el hilo conductor de una comunicación muy activa intra e interétnica, como indica Robinson (2000, p. 97) para el caso Kofan: "Shamans were visiting each other and sharing yage, kinfolk would expend weeks at each other's villages, often from neighbouring tribes, drink yage and return home". El chamanismo de 
la ayahuasca, fiel a su vocación comunicativa, muestra abundantes indicios de una ecumene: cantos, dibujos y mitos desbordan límites étnicos o lingüísticos. El uso de otras lenguas en los cantos -pensemos en el prestigio de los cantos Kulina entre los Pano, o en el uso de un pseudo-quechua en los cantos shipibo (Roe, 1982, p. 89) denuncia un comercio entre etnias, o más exactamente entre practicantes de etnias diferentes, y la noción de que el saber de la ayahuasca es constitutivamente extranjero. Incluso cuando la práctica chamánica se realiza en círculos restringidos para evitar agresiones mágicas que podrían venir de chamanes ajenos (la necesidad de curar a los parientes próximos aparece por ello mismo como un incentivo importante para la iniciación) el saber chamánico como tal es supraclánico (Chaumeil, 1983, p. 246) o supraétnico. La liana banisteriopsis ha sido un ítem importante en el comercio entre diferentes pueblos de la selva, o incluso entre las Tierras Altas y las Tierras Bajas (Ramírez Jara; Pinzón Castaño, 1992, p. 292) siguiendo los pasos del propio chamanismo, que ofrece notables ejemplos de especialistas itinerantes que ejercen su actividad en regiones muy amplias. Como indica Peter Gow (1996) la ayahuasca no es un rasgo de la primitividad amazónica, sino el resultado de un proceso mestizo al que no fue ajena la propia empresa misionera, con su práctica de concentrar pueblos diferentes en misiones ribereñas, desde Mainas a la actualidad. Según Gow, el chamanismo de la ayahuasca, y sobre todo su carácter terapéutico, irradiaría desde el espacio colonial y urbano en dirección a la selva - donde los pueblos más aislados, como los Huaorani, no conocen la ayahuasca o le dan un papel menos central - y no al contrario. Pero sería excesivo - el propio Gow hace esa restricción a su tesis - limitar la historia de la ayahuasca a ese eje de colonización que comunica ciudades amazónicas, mestizos ribereños y grupos indígenas del interior, o a ese flujo en que la ayahuasca retorna, moralizada y medicalizada, a su lugar de origen remoto. La no-autoctonia de la ayahuasca tiene muchas otras manifestaciones, y una historia tal vez más larga, con más idas y vueltas. El uso terapéutico de la ayahuasca por los Yaminawa es una novedad tal vez mestiza; pero, potenciado por el prestigio de la selva, se destina a una clientela principalmente mestiza y blanca, y se sobrepone de todos modos a un 
uso no terapéutico aun vivo en parte. La ayahuasca es, por ejemplo, uno de los ítenes básicos de la civilización ucayalina - históricamente mestiza pero simbólicamente india - que se manifiesta, también, por ejemplo, en un estilo grafico (Shipibo-Conibo, Piro, Kaxinawa) íntimamente ligado a las visones que ella produce, y a la que podrían encontrarse probablemente paralelos en la región del río Negro, donde la ayahuasca acompaña una koiné cultural semejante. La adopción de la ayahuasca es con frecuencia un signo de integración en ese proceso civilizador local, que pasa a incorporar en su seno prácticas anteriores. Véase el caso de los Cashibo, que aún relataron a Edwin Frank (1994, p. 181) una situación anterior a su adopción de los modos Shipibo, cuando no usaban la ayahuasca, y el chamanismo se afanaba en prácticas realizadas a la sombra de la samauma - como hemos visto, un agente visionario ampliamente desplazado por la ayahuasca. La magia de caza de los Amahuaca (Carneiro, 1970) incluía las mismas ordalías que actualmente componen, bajo la égida de la ayahuasca, el proceso de iniciación del chamán Yaminawa. Los Kulina recuerdan haber aprendido el uso de la ayahuasca de los Kanamari, que a su vez la tomaron de los Kaxinawa (Lorrain, 1994, p. 132). Los Matsiguenga, aunque consideren la ayahuasca como un don de los Sangarite ancestrales, dan pistas para sospechar un uso reciente, tal vez datado del trabajo con los madereros en el río Urubamba a mediados del siglo XX (Shepard, 2005, p. 201-203). Cualquier afirmación sobre el uso o no uso de ayahuasca por tal o cual pueblo indígena de la región basada en informaciones de hace dos o tres décadas debería probablemente revisarse a la luz de relatos más recientes; lo mismo podría decirse sobre cualquier explicación primitivista.

Sería aventurado atribuir a la ayahuasca un papel determinante en ese proceso histórico, que en último término no pasa de una ilustración más del error en que se caía cada vez que el mundo amazónico era visto como un racimo de mónadas aisladas, antes o después de la llegada de los blancos. Pero es innegable que la ayahuasca proporciona un registro especialmente expresivo de ese sistema regional. Ese conjunto totémico formado por los etnónimos de los pueblos de la región, formados a partir de nombres de animales o plantas que se repiten 
de una lengua a otra - en cada conjunto etno-lingüístico tenemos un pueblo-jaguar, un pueblo-pecarí, etc. - sugiere una versión sociológica del perspectivismo amerindio (Viveiros de Castro, 1996) donde la diversidad étnica queda englobada por la diversidad de especies: no hay como distinguir, en muchas de esas narraciones míticas, a esos jaguares o pecaríes que son humanos de esos humanos que se llaman jaguares o pecaríes - y donde el mimos agente visionario que faculta la comunicación con espíritus de otras especies cumple el mismo papel en la comunicación, amistosa o bélica, entre las diversas etnias. La ayahuasca viene a ser en ese contexto - juguemos a la tecnología imaginaria - una especie de aloscopio, un instrumento capaz de producir imágenes inteligibles del otro - sea un otro sociológico o cosmológico - dando así un motivo y una clave para la comunicación.

Esa comunicación no es menos intensa con esa dimensión que, para usar un término ya no muy exacto, llamaremos "el mundo de los blancos". Al lado de la imaginería selvática comúnmente relatada en las visiones de la ayahuasca - anacondas, jaguares, espíritus de plantas - es innegable el cosmopolitismo, o incluso el futurismo, que igualmente las puebla. Ver ciudades, metrópolis mucho más allá de las modestas ciudades regionales, dotadas de rascacielos. Fantásticas maquinarias o hasta aeropuertos para naves espaciales, no es menos común que ver anacondas o jaguares, y es necesario notar que ese futurismo va más allá del anécdota pintoresca, reflejando el valor extra-local o exótico del chamanismo y de la ayahuasca en sí.

Un famoso chamán Shipibo-Conibo (Arévalo-Varela, 1986) especifica el papel de esa ciudad en la iniciación del hechicero, haciendo eco a declaraciones similares de muchos otros chamanes dentro y fuera del área de la ayahuasca. La "ciudad" que desde el punto de vista de los blancos podía ser el emblema del mundo moderno frente a la aldea o la selva de los indios, es en la visión indígena un centro de poder y de saber que no necesariamente se identifica con los blancos; véase, por ejemplo, la versión Yekuana, donde esas ciudades "de espejos" identificadas con las ciudades de los blancos son consideradas creaciones del demiurgo Wanadi. (Guss, 1989, p. 58-59)

La demanda de chamanes de la selva por parte de la clientela blanca de la amazonia o aun de la clase media urbana de las nacio- 
nes amazónicas da continuidad a un interés por la magia nativa que nunca ha dejado de manifestarse desde los inicios de la colonia, y que naturalmente se aplicó también a las plantas psicoactivas - presentes de modo mucho más marginal, pero no por eso menos interesante, en la propia tradición europea. El interés de los blancos por la ayahuasca no tuvo que esperar a la generación beat, y tuvo expresiones tan sorprendentes como la de ese misionero franciscano de inicio del siglo XX que los Sibundoy (Ramírez de Jara; Castaño Pinzón, 2000, p. 293; PENA, 2000, p. 65) recuerdan como gran conocedor de la ayahuasca. La ayahuasca, vista como fármaco o como vehículo trascendente, es siempre una adecuada objetivación de los poderes del chaman indígena, que puede ser así incorporada en nuevas religiones que combinan en dosis y modalidades diferentes cristianismo, espiritismo e indianismo romántico - siendo la Iglesia del Santo Daime, la Unión del Vegetal y la Barquinha los exponentes más clásicos de un sector religioso en expansión, que cuenta con expresiones cada vez más ambiciosas en su programa de hibridación, como es el caso del Caminho Vermelho (una derivación de la Native Church norteamericana). Un paso más allá, o más acá, en ese camino, es la creciente (y por supuesto controversa) proliferación de chamanes "blancos" que usan la ayahuasca (Labate; Cavnar, 2014) sea en la vecindad y con el saber recibido de otros chamanes, sea en la ciudad como una especie de agentes autorizados de una iglesia chamánica indígena (Oliveira, 2012). La ayahuasca en sí, más que los propios chamanes indígenas, ha sido el protagonista de lo más parecido que podemos encontrar a una contraevangelizacion indianista que, a partir de la Amazonia, ha insertado temas y elementos rituales indígenas en el mundo religioso de los "blancos".

No sin que esos híbridos sean traídos de vuelta listos para nuevas hibridaciones. La ayahuasca baniwa "de los pajés" (chamanes) diferente de la ayahuasca "de danzar" antes citada, fue introducida por Venancio Kamiko, profeta fundador de uno de los numerosos contra-cristianismos del Río Negro (Wright, 2005, p. 93). La religión del Santo Daime, "religión pura de la ayahuasca" puede volver a la aldea Kaxinawa en una versión reindigenizada donde, junto con el crucero en la puerta, las imágenes de santos y la disposición del público, (filas separadas de hombres y mujeres) propios de los rituales daimistas, 
se reserva un lugar a los cantos tradicionales nativos (en la aldea Novo Futuro, conforme Weber, 2006, p. 178-181). La expansión de la ayahuasca, muy considerable ya en los Estados Unidos y en Europa, alcanza también - provocando un nuevo capítulo de discusiones a respecto de la autenticidad indígena - las prácticas chamánicas de pueblos indígenas muy distantes de la Alta Amazonia, como es el caso de los Guaraní de la aldea de Biguaçú, en el litoral sur de Santa Catarina (De Rose, 2010). Aunque pueda ser más fácilmente entendida como reindigenización de una práctica adquirida a través de las redes interamericanas de la New Age (junto con, por ejemplo, la variante guaraní de la sweat-lodge, o temascal) la tesis local de que ese uso representaría la recuperación de una práctica antigua en desuso está en último término condenada a verificarse: es difícil que haya algún lugar en la América Indígena, o incluso en la Europa despaganizada y secularizada, donde la ayahuasca no pueda reivindicar la herencia de los viejos piscoactivos abandonados.

\section{Teorias}

La mitología referida a la ayahuasca, o en particular a su origen, no forma un corpus específico segregado del resto de esa mitología amerindia que se puede encontrar dentro o fuera del área de uso de la ayahuasca. El mito huaorani al que antes se aludió desarrolla el tema del desanidador de pájaros, el mismo cuya versión bororo inicia las Mitológicas de Levi-Strauss. Otros temas son igualmente recurrentes en el corpus general de la mitología amerindia: el origen de la ayahuasca a partir del desmembramiento de un personaje, o de la siembra de partes de su cuerpo (Reichel-Dolmatoff, 1975, p. 134-136); o su germinación en sus distintas variedades, a partir de los órganos del cuerpo sepultado de un chaman o un jefe - eventualmente un Inca genérico, como en Luna e Amaringo (1999, p. 50); o su obtención de un dueño original no humano (como las anacondas, que devorando al protagonista le hacen conocer los secretos de la bebida (conforme Lagrou, 2000, p. 33-35). En todos los casos, la ayahuasca se instala en medio de una mitología preexistente - o, evitando todo rasgo de 
historia conjetural, en la misma mitología en la que participan pueblos que no conocen la ayahuasca.

Yo mismo sugerí hace unos años (Calavia Sáez, 2000) dos tipos de mitos referidos a la ayahuasca, que remiten respectivamente al mundo del río y al mundo del interior de la selva. Los primeros trataban de una relación con el pueblo de las aguas, dueño de la poción - especialmente con las anacondas - y de la adquisición de ese conocimiento en el curso de un intercambio conyugal y de perspectivas. Los segundos sobre la separación entre vivos y muertos (el origen de la ayahuasca y el de la muerte se confunden, y la ayahuasca antes de comunicar con los muertos posibilitó su distanciamiento), y sobre expediciones guerreras. Esa distinción tiene sentido por lo menos en el caso de los mitos Pano, en armonía con esa distinción riverside/backwoods presente tanto en las ideologías locales como en las teorías de los etnólogos - incluyendo en ella la tesis de la ayahuasca mestiza de Gow, que coincidiría con la primera variante. Pero, como cualquier clasificación de mitos que intentemos, se agota en ese contexto sin controlar la materia mítica, que es inmune a clasificaciones: cada clasificación puede ser útil para una interpretación local, de la cual los mitos, gracias a su calidad transformativa, se pueden escapar un minuto más tarde o un meandro del río más adelante. Mi clasificación no atendería, por ejemplo, a los mitos Tukano, que funden ambas opciones. Con esas mismas restricciones se podría sugerir otra distinción, más formal que temática, que quizás sea útil para algunas consideraciones que ofrezco más tarde: algunos mitos presentan a la ayahuasca como operador de transformaciones; otros, a la propia ayahuasca como avatar de esas transformaciones. O sea, por este lado mitos que describen la ayahuasca como transformación de un cuerpo: el cuerpo de Yube o del Inka, el dedo de una mujer Desana, la cola de la anaconda celeste. Por aquel otro, mitos que describen no tanto el origen de la ayahuasca, sino el modo en que los humanos aprendieron a usarla, adquiriendo con ello una especie de clave general del carácter transformacional del mundo. Una mitología como la Yaminawa, que constantemente narra encuentros con seres animados e inanimados que en el curso de la acción se revelan humanos y establecen relaciones con el protagonista humano inicial, 
parecen la trascripción de una vasta experiencia con la ayahuasca. El corpus narrativo de la ayahuasca, de hecho, está compuesto, mucho más que de narraciones "tradicionales", de experiencias visionarias individuales. La literatura es rica en ese tipo de testimonios, que al mismo tiempo se nutren del acervo mitológico y contribuyen a su renovación (conforme las narraciones de Prohaño, Peña y Payaguaje en Luna; White, 2000).

Más interesante que una impracticable síntesis de la mitología puede ser observar cómo la mitología se articula con el uso de la ayahuasca. Un informante de Lagrou (2000, p. 32-33) observa que concentrar la mente en un mito en el momento de tomar la ayahuasca es el modo correcto de prepararse para las visiones que llegan. Vale la pena notar que los procesos de iniciación están directamente ligados a esas mitologías; la iniciación es un primer viaje que prenuncia la práctica viajera que seguirá. El episodio central de la experiencia Sharanahua o Yaminawa es, como hemos dicho, semejante al mito en que las anacondas devoran al primer bebedor humano de ayahuasca, y lo mismo se puede decir de narraciones que describen viajes. Los mitos son al mismo tiempo guiones de la visión y guías de su interpretación. En un nivel más sofisticado, Townsley (1993) muestra cómo los cantos chamánicos que necesariamente acompañan a las visiones, (cantos no narrativos y cifrados en una lengua hermética que es el núcleo del saber exclusivo de los chamanes) son versiones "líricas" de los mitos, plagadas de alusiones sutiles a ellos. O sea, podríamos decir, que mantienen la misma relación con ellos que la poesía renacentista establecía con la mitología clásica. Citas casi imperceptibles que iluminan el sentido de los cantos, pero sólo para quienes acumulen erudición suficiente. Lo que llamamos cosmologías indígenas (a veces por $\mathrm{n}$ supera el recelo de hablar abiertamente de filosofías indígenas) proviene de este tipo de trabajo de selección y articulación de narraciones míticas, enriquecido con experiencias chamánicas, dando lugar a extensiones o nuevas versiones de estos mitos, o a comentarios metanarrativos.

No fue otro el modo en que la filosofía occidental se desarrolló como comentario de la historia sagrada, haciendo abundante uso de sus episodios. Como yo mismo ya señalé (Calavia Sáez, 2002) es 
función de los narradores organizar conjuntos mitológicos a partir de un acervo común, fragmentar o componer narraciones a partir de él. Esa tarea distributiva forja el argumento de la cosmología. Un buen ejemplo puede ser el del mito Yawanawa que reúne en un único relato los mitos de origen de la ayahuasca "del río" y "de tierra adentro". El personaje que, casado con una mujer anaconda, conoce la ayahuasca y es casi devorado por sus cuñados serpientes es el jefe de cuya tumba brota la liana, y cuyo lamento funeral llevará a sus seguidores a elevarse hasta el cielo y conocer el mundo de los muertos. El relato, uniendo en un mismo argumento dos narraciones distintas, sintetiza en un único trazo - del fondo de las aguas hasta el cielo pasando por la muerte - una visión general del mundo.

No fue necesario, por eso, que las religiones ayahuasqueras, más o menos ligadas al cristianismo, viniesen a extraer cosmologías de la práctica visionaria. Ni que Reichel-Dolmatoff ( 1975) hiciese lo mismo abstrayendo de esa práctica una serie de "energías" que le permitieran una descripción del mundo más acorde al estilo intelectual de Occidente. Esa filosofía ya se encuentra en los mitos y en comentarios nativos mucho más presos a idiomas sensibles, y capaces por ello de efectos de pensamiento menos familiares. Un buen ejemplo puede ser el del conjunto Pano - aunque sus líneas generales se puedan identificar en otras partes, como entre los Yekuana, situados al otro extremo de la región de la ayahuasca, que establecen las mismas ecuaciones entre pinturas corporales, visiones, pieles animales y grafismo (Guss, 1989, p. 102-103, 109-110). Su punto de partida puede ser esa condición de grafismo que se atribuye a las visiones de la ayahuasca, que se encuentra también en algunas pieles de animales, en la pintura sobre cerámica, en los tejidos y en la pintura corporal (la categoría kaxinawa kënë - conforme Lagrou (2007, p. 108 y ss) - se aplica igualmente a diseños humanos y patrones naturales, subrayando en ambos casos una potencia cultural y expresiva) pero que también pueden ser sinestésicamente identificados en los cantos: véase la anécdota transmitida por Gebhart-Sayer (apud Cunha, 1998, p. 14) de las mujeres shipibo que, comenzando la ornamentación en los lados opuestos de una gran vasija, conseguían coordinar sus trazos por medio de los cantos con 
los que acompañaban el trabajo. La ayahuasca cumple un papel de mediación entre pueblos (incluyendo pueblos no humanos en sentido estricto) pero lo hace sintetizando al mismo tiempo vehículos de expresión: el visual, el musical, el verbal. Los dibujos son cantos que a su vez son visiones o pieles, y que constituyen la escritura de ese libro (escrito por el colibrí, o guardado en la Casa de Dios, extrahumano en cualquier caso) donde constan los secretos chamánicos ${ }^{12}$. La cura del chamán Shipibo consiste en modificar por medio de sus cantos el dibujo que la ayahuasca le permite ver proyectado sobre el paciente, evitando deformaciones, o dibujos aislados que interfieran en la trama regular. (Gebhart-Sayer, 2000)

Pero esa superficie gráfica que atraviesa fronteras entre cuerpos o entre modos de expresión es capaz también de trasponer barreras topológicas entre interior y exterior. Efectivamente, la mitología de la ayahuasca se podría describir como un gran juego circular de englobamientos: el hombre, pintado con los mismos patrones gráficos de la anaconda, absorbe la ayahuasca, identificada con la anaconda; el simple encuentro con la anaconda puede causar las sensaciones propias de la ayahuasca; el bebedor se torna anaconda, huele como una anaconda, devora anacondas ${ }^{13}$ y ve anacondas que a su vez lo devoran. Se puede aventurar que el modo de predación de la anaconda, que se traga enteras a sus víctimas - un destino reservado a los protagonistas de varios mitos de origen de la ayahuasca - haya sido un factor importante para establecer su valor simbólico predominante ${ }^{14}$ en una práctica que gira en torno de esa paradoja topológica: es absorbiendo la planta como el hombre consigue ver los espíritus que ella contiene, es tornándose continente de la ayahuasca como el visionario consigue viajar en el interior de esta. El proceso interior/exterior/interior es continuo y puede ser reducido a superficie: los cazadores Kaxinawá identifican en la piel de la serpiente formas de animales que deberán cazar, porque las figuras animales están contenidas en ese diseño en principio no - figurativo (Lagrou, 2007, p. 71). Las formas kene, geométricas, y las formas dami, figurativas, son así resultado de énfasis diferentes de la mirada, que se alternan como fondo y forma en las artes vinculadas al mundo de la ayahuasca (Lagrou, 2007, p. 69; GUSS, 
1989, p. 108-109). Lo mismo puede decirse de la sucesión, muchas veces descrita en los relatos de visiones, de patrones geométricos y figuras, que pueden entenderse como diferentes distancias de la mirada que la ayahuasca hace posible. Como dice Deshayes (2000, p. 158) la alternativa figurativo/no figurativo no tiene sentido en términos Kaxinawá: es la mirada indirecta, o la concentración en la sombra o la periferia de la visión, lo que sirve para revelar la transformación en las visiones (Deshayes, 2000, p. 207 y ss). Quizás pueda entenderse como una versión sonora de ese movimiento el estilo polifónico de los cantos de la ayahuasca, donde las voces alternadamente suben a un primer plano o se relegan a un fondo continuo en segundo o tercer plano. En resumen, la ayahuasca parece desencadenar un modo de percepción que, en un único movimiento, transforma en superficie continua interior y exterior, fondo y forma, inscribiendo en ese vaivén la diversidad de los seres.

Si poco antes aludimos a la poesía renacentista y al continuum teología-filosofía del occidente, podríamos extender ahora esa comparación al dominio de las artes pláticas europeas, y al papel que la perspectiva jugó en ellas. Un fascinante artículo, poco conocido, de Ortega y Gasset (1949) proponía entender toda la historia de la pintura occidental como una trayectoria de distanciamiento del punto de vista del observador con relación a su objeto. La idea central es la oposición entre una mirada próxima, que da volumen y corporeidad al objeto y lo aísla de su contexto, y una mirada distante que privilegia el espacio vacío y sublima los cuerpos. Primero - como en el arte del Quattrocento - el ojo avanza sobre la forma vista; después se contrae, dando lugar al espacio. Y esa mirada más distante es también la más subjetiva, como ocurre en el impresionismo, con la cromatización del mundo y la disgregación de las formas: el pintor ya no se ocupa de la realidad, sino de la sensación. El proceso - añade Ortega - no se detiene en la superficie del ojo, y se refugia más adentro: así, Cezanne y los cubistas recuperan el volumen, pero ya es un volumen a priori, presente en el intelecto del artista e impuesto al exterior. En el lapso de cinco siglos los pintores pintan primero cosas, después sensaciones, después ideas, y a cada punto de esa trayectoria corresponde también 
una concepción filosófica: realismo, subjetivismo, razón trascendental. Ortega sugería una filosofía del arte que los historiadores continuarían revelando durante l siglo XX. Como indica Panofsky (1983) el auge de la pintura perspectiva, en el renacimiento clásico, encarnó la empresa de representar, más allá de objetos individuales, el espacio, o esa extensión de la materia que constituía su denominador común. Más que una simple representación, más que una prueba de maestría técnica, la pintura perspectiva es un tema de reflexión filosófica (la perspectiva siempre sirvió a los filósofos como un ejemplo privilegiado del engaño de los sentidos) y, aún más, una demostración "de laboratorio" o al menos "de taller" de que el mundo está compuesto de materia indistinta.

La ayahuasca proporciona una evidencia visual equivalente para el pensamiento indígena, aunque apunte a perceptos muy diferentes. Sobre todo, porque el movimiento no es monopolio de un sujeto observador humano. Sus objetos son móviles: son, en realidad, otros sujetos que se aproximan o apartan del visionario, en general tumbado y quieto en su hamaca. En lugar de confinar las capacidades humanas en el ojo o en la mente del observador, la ayahuasca las desinterioriza, mostrando esas capacidades repartidas por el ancho mundo, y transformando en escritura (entiéndase, una escritura original, no dependiente del Verbo) lo que para una visión común serían cuerpos, lenguajes, especies o etnias discretas. Nada, dígase de paso, que recuerde a una vaga fusión mística de todo: más bien a una infinita fragmentación que, en lugar de resolverse mediante reducciones unificadoras, se ordena según una vasta combinatoria ${ }^{15}$.

\section{Más Teorías}

En la sumaria revisión de la literatura etnográfica que cabe en este artículo es posible identificar con facilidad lo que la ayahuasca no es. No es una tradición repetida con variables accesorias de un pueblo a otro. No es la realización cultural de las virtudes de un principio activo. No es un capítulo del chamanismo o de la cultura. No es una religión. En rigor, la ayahuasca no es nada, o mejor dicho no es nada más. No trae a colación mitos, rituales o formas sociales nuevas: incluso sus 
propiedades psicoactivas continúan - a veces en tono menor - las de otras "plantas de poder". Pero en esa condición la ayahuasca organiza redes: de información chamánica, de relaciones comerciales o bélicas, de imágenes del otro, de psicoactivos. El objeto de este texto es huidizo. A pretexto de la ayahuasca se puede estar hablando de perspectivismo amerindio, de la labilidad del chamanismo, o de una socialidad indígena no amarrada a cuerpos sólidos, o del carácter transformacional de los mitos: tópicos todos ellos que pueden identificarse, lejos del ámbito de la ayahuasca, en buena parte de la etnología amazónica - o no amazónica - actual. ¿Estaríamos simplemente proyectando conceptos tomados de una moda intelectual? Creo que sí, con la salvedad de que se trata de una moda intelectual indígena y de que es la propia ayahuasca, y el modo de percepción que ella proporciona, lo que se está proyectando sobre una cosmología y una sociología. La ayahuasca, hoy, no es indígena por origen sino por elección: dejando - cada vez más - de ser un elemento dentro de un conjunto de psicoactivos para ser su resumen, ella es uno de los modos, quizás el más ágil, de dar coherencia a la trama de relaciones que componen la vida actual de los índios.

\section{Notas}

1 Este artículo, con algunas modificaciones ligeras y alguna ampliación de peso, es el mismo publicado anteriormente, em inglés, bajo el título $A$ vine network (Sáez, 2011). Las alteraciones citadas son, sin embargo, suficientes para que lo considere su versión principal.

2 Usaremos preferentemente el término ayahuasca, para evitar la confusión que resultaría de alternar términos como shori, huni, miyabu, kàhi (sus equivalentes Yaminawa, Kaxinawa, Huaorani, Yekuana) etc. Aparecerá algunas veces yagé (el termino tukano, muy usado también en la literatura, y cipó, una designación común en Brasil.

3 Ott (apud Bianchi, 2005, p. 326) sugiere de hecho la reducción de toda esa diversidad a una formula básica común, que el llama pharmahuasca, un mínimo común denominador compuesto de fuentes de DMT y betacarbolinas.

4 Publicado originalmente en 1908, aunque relate una experiencia de 1852.

5 Esa función del tabaco como moneda corriente en as transacciones con el más allá ha pasado al dominio de la religiosidad popular brasileña: el tabaco es la ofrenda más común que se puede dedicar a los seres sobrenaturales, 
en contextos codificados como el de la Umbanda o en el mundo mas o menos fluido de las creencias amazónicas.

6 Los Matsiguenga (Shepard, 2005, p. 202) prefieren las variedades cultivadas, con recelo del carácter tóxico que puedan tener las silvestres.

7 Furst (1990, p. 15) indica que solo la practica chamánica explica que el número de los psicoactivos conocidos en el hemisferio americano supere al de todos los otros continentes juntos.

8 Según el mismo autor, aunque la decocción sea administrada a los jóvenes iniciantes, no hay ninguna referencia a visiones (el autor no explica si esa ayahuasca incluye psychotria; por lo demás, los Huaorani tampoco utilizan otras plantas psicoactivas comunes, como la datura o el propio tabaco).

9 Esa potencia especifica de comunicar con los muertos esta presente en la propia etimología de ayahuasca - cuerda de los muertos, en quéchua - pero también en usos como los del "caapi dos pajés" baniwa (Wright, 2005) donde es esa función lo que diferencia la ayahuasca del paricá.

${ }^{10}$ Hugh Jones (1996; p. 39) cita sin embargo el uso de otro tipo de yagé, fish-yagé.

11 Esos mariri serian aun realizados en aldeas Yaminawa más remotas, como la del río Iaco.

${ }_{12}$ Los dibujos son la escritura de los espíritus - yushi (conforme Lagrou, 2007, p. 70). Igualmente, el relato mítico es para los Kaxinawá, antsa kene, es decir, dibujo hablado. (Deshayes, 2000, p. 190)

13 Conforme Cofacci de Lima (2000, p. 132-134). La dieta prescrita a los jóvenes Yawanawá que están siendo iniciados - pequeños animales como ratones, etc. acompañando un consumo constante de ayahuasca - obedece a esa identificación: ellos deben comer lo que comen los boideos. En diversas variantes de la iniciación chamánica Pano, los novicios deben ingerir el corazón, los excrementos o alguna otra sustancia extraída de la serpiente, comer su carne o chupar su lengua.

14 Eso es visible por lo menos en el caso Pano que estoy comentando donde (conforme el comentario para el caso katukina de Coffacci de Lima (2000, p. 215) su presencia en el imaginario chamánico supera en mucho a la del jaguar.

15 Conforme Descola (2006, p. 241-243) para un relato de la experiencia de la ayahuasca de un intelectual europeo ajeno a la cultura psicodélica.

\section{Referências}

ABREU, João Capistrano. Ra-txa Hu-ni-ku-i a língua dos caxinauas do Rio Ibuacu - Gramática, textos e vocabulário caxinauas. Ed. Capistrano de Abreu, 1941. [1914].

ALVAREZ, Ricardo. Ícaros: crimen y venganza. Revista de misiones dominicanas del Peru, Peru, p. 20-25, 1964.

ARÊVALO-VARELA, Guillermo. El ayahuasca y el curandero ShipiboConibo del Ucayali, América Indígena, XLVI, n. 1, p. 147-161, 1986. 
BIANCHI, Antonio. Ayahuasca e xamanismo indígena na selva peruana: o lento caminho da conquista. In: LABATE, Beatriz Caiuby; GOULART, Sandra. O uso ritual das plantas de poder. Campinas: Mercado de Letras-FAPESP, 2005. p. 319-329.

BROWN, Michael. Tsewa's gift: magic and meaning in an Amazonian society. Washington DC: Smithsonian Institution Press, 1985.

BUCHILLET, Dominique. Nobody is there to hear: desana therapeutic incantations. In: LANGDON, Esther Jean; BAER, Gerhard. Portals of power: Shamanism in South America. Albuquerque: University of New Mexico Press, 1992. p. 211-230.

CALAVIA SÁEZ, Oscar. Mythologies of the Vine. In: LUNA, Luis Eduardo; STEVEN, White. Ayahuasca reader. Santa Fe: Synergetic press, 2000. p. 36-40.

. A vine network. In: LABATE, Beatriz. The internalization of ayahuasca. Ed. Munster: Lit Verlag, 2011. p. 131-144.

CALAVIA SÁEZ, Oscar; CARID NAVEIRA, Miguel; PÉREZ GIL, Laura. O saber é estranho e amargo: sociologia e mitologia do conhecimento entre os Yaminawa. Revista Campos, Curitiba: PPGAS-UFPR, n. 4, p. 9-28, 2003.

CALAVIA SÁEZ, Oscar. A variação mítica como reflexão. Revista de Antropologia, Florianópolis, n. 45, v. 1, p. 7-36, 2002.

CARNEIRO DA CUNHA, Manuela. Pontos de vista sobre a floresta: xamanismo e tradução. Mana, Rio de Janeiro: PPGAS-MNRJ, 4 (1), 1998. p. 7-22.

CARNEIRO, Robert L. Hunting and hunting magic among the Amahuaca. Ethnology, USA, v. 9, n. 4, 1970.

CHAUMEIL, Jean Pierre. Voir, savoir, pouvoir: le chamanisme chez les Yagua du nord-est peruvien. Paris: Editions de l'Ecole des Hautes Etudes en Sciences Sociales, 1983.

DE ROSE, Isabel Santana. Projeto de Pesquisa de Doutorado. 2007. Tese (Doutorado em Antropologia Social) - Universidade Federal de Santa Catarina, Florianópolis, 2007.

DESHAYES, Patrick. Les mots, les images et leur maladies. Paris: Loris Talmart, 2000. $1,2003$. . L'Ayawaska n'est pas un hallucinogène. Psychotropes, USA, n. 8, FRANK, Erwin. Los Uni/Cashibo. In: SANTOS, F.; BARCLAY, Federica. Guía etnográfica de la Alta Amazonía. II FLACSO/IFEA, Quito, 1994. 
FREEDMAN, Francoise Barbira. The Jaguar who would not say her prayers: changing polarities in upper Amazon shamanism. In: LUNA, Luis Eduardo; WHITE, Steven. Ayahuasca Reader. Santa Fe: Synergetic Press, 2000. p. 113-119.

FURST, Peter. Alucinogênios e cultura. Lisboa: Ulisseia, 1990. [1976]. GEBHART SAYER, Angelika. Design Therapy. In: LUNA, Luis Eduardo; WHITE, Steven. Ayahuasca Reader. Santa Fe: Synergetic Press, 2000. p. 127-132.

GOW, Peter. River people: shamanism and history in western Amazonia. In: THOMAS, N.; HUMPHREY, C. Shamanism, history and the state. The University of Michigan Press, 1996. p. 90-113.

GUSS, David. To weave and sing: art, symbol and narrative in the South American Rainforest. Berkeley: University of California Press, 1989.

HUGH-JONES, Stephen. Shamans, prophets, priests and pastors. In: THOMAS, N.; HUMPHREY, C. Shamanism, history and the state. The University of Michigan Press, 1996. p. 32-75.

ILLIUS, Bruno. The concept of Nihue among the Shipibo-Conibo of Eastern Peru. In: LANGDON, Esther Jean; BAER, Gerhard. Portals of power: shamanism in south America. Albuquerque: University of New Mexico Press, 1992. p. 63-77.

LABATE, Beatriz Caiuby; CAVNAR, Clancy. Ayahuasca shamanism. In: The Amazon and beyond. Oxford University Press, USA, 2014.

LAGROU, Elsje. Two ayahuasca myths from the cashinahua of northwestern Brazil. In: LUNA, Luis Eduardo; WHITE, Steven. Ayahuasca Reader. Santa Fe: Synergetic Press, 2000. p. 31-35.

A fluidez da forma: arte, alteridade e agencia em uma sociedade amazônica (Kaxinawa, Acre). Rio de Janeiro, TopBooks, 2007.

LANGDON, Esther Jean. Dau: shamanic power in siona religion and medicine. In: LANGDON, Esther Jean; BAER, Gerhard. Portals of power: shamanism in South America. Albuquerque: University of New Mexico Press, 1992. p. 41-61.

. A visit to the second heaven: a siona narrative of the yage experience. In: LUNA, Luis Eduardo; WHITE, Steven. Ayahuasca Reader. Santa Fe: Synergetic Press, 2000. p. 21-30.

. Prefacio. In: LABATE, Beatriz Caiuby; GOULART, Sandra. O uso ritual das plantas de poder. Campinas: Mercado de Letras-FAPESP, 2005. p. 13-26.

LATOUR, Bruno. Reassembling the social: an introduction to actornetwork theory. Oxford University Press, 2007. 
LECLERC, Frederique. Los noi rao. In: CALAVIA SÁEZ, Oscar; LENAERTS, Marc; SPADAFORA, Ana Maria. Paraíso abierto, jardines cerrados:

pueblos indígenas, saberes y biodiversidad. Quito: Abya-Yala, 2004. p. 151176.

LIMA, Edilene Coffaci. Com os olhos da serpente: homens, animais e espíritos nas concepções katukina sobre a natureza. Tese de Doutorado. Universidade de São Paulo, 2000.

LORRAIN, Claire. Making ancestors. The symbolism, economics and politics of gender among the Kulina of Southwest Amazonia. PHD Thesis Dept. of Social Anthropology \& Kings College Cambridger University, 1994.

LUNA, Luis Eduardo. Narrativas da alteridade: A ayahuasca e o motivo de transformação em animal. In: LABATE, Beatriz Caiuby; GOULART, Sandra. O uso ritual das plantas de poder. Campinas: Mercado de LetrasFAPESP, 2005. p. 333-352.

LUNA, Luis Eduardo; AMARINGO, Pablo. Ayahuasca visions: the religious iconography of a peruvian shaman. Berkeley: North Atlantic Books, 1999 [1991].

MILLER-WEISBERGER, Jonathan. A huaorani myth of the first miyabu. In: LUNA, Luis Eduardo; WHITE, Steven. Ayahuasca Reader. Santa Fe: Synergetic Press, 2000. p. 41-45.

MOTA, Clarice Novaes. Jurema e identidades: um ensaio sobre a diáspora de uma planta. In: LABATE, Beatriz Caiuby; GOULART, Sandra. O uso ritual das plantas de poder. Campinas: Mercado de Letras-FAPESP, p. 219-237, 2005.

OLIVEIRA, Aline Ferreira. Yawa-nawa: alianças e pajés nas cidades. 2012. Dissertação (Mestrado em Antropologia Social)-Universidade Federal de Santa Catarina, Florianópolis, 2012.

ORTEGA Y GASSET, Jose. Sobre el punto de vista en las artes. In: Goethe desde dentro. Madrid: Revista de Occidente, 1949 [1924]. p. 81-99.

PANOFSKY, Erwin. La perspectiva como "forma simbólica". Barcelona: Tusquets, 1983.

PENA, Don Hilário. Light of this world. In: LUNA, Luis Eduardo; WHITE, Steven. Ayahuasca Reader. Santa Fe: Synergetic Press, 2000. p. 63-66.

PÉREZ GIL, Laura. Chamanismo y modernidad: fundamentos etnográficos de un proceso histórico. In: CALAVIA SÁEZ, O.; LENAERTS, M.; SPADAFORA, A. M. Paraíso abierto, jardines cerrados: Pueblos indígenas y biodiversidad. Quito: Abya-Yala, 2004. 
POLLOCK, Donald. Culina Shamanism: gender, power and knowledge. In: LANGDON, Esther Jean; BAER, Gerhard. Portals of Power: Shamanism in South America. Albuquerque: University of New Mexico Press, 1992. p. 25-40.

RAMIREZ DE JARA M., Clemencia; PINZON CASTAÑO, Carlos Ernesto. Sibundoy shamanism and popular culture in Colombia. In: LANGDON, Esther Jean; BAER, Gerhard. Portals of Power: Shamanism in South America. Albuquerque: University of New Mexico Press, 1992.

REICHEL-DOLMATOFF, Gerardo. The shaman and the jaguar: a study of narcotic drugs amongthe indians of Colombia. Philadelphia: Temple University Press, 1975.

ROBINSON, Scott. Yage Nostalgia. In: LUNA, Luis Eduardo; WHITE, Steven. Ayahuasca Reader. Santa Fe: Synergetic Press, 2000.

ROE, Peter G. The cosmic zygote: Cosmology in the Amazon Basin. Rutgers University Press, New Jersey, 1982.

SISKIND, Janet. To hunt in the morning. Oxford University Press, 1973. SPRUCE, Richard. On some remarkable narcotics of the Amazon valley and Orinoco. In: LUNA, Luis Eduardo; WHITE, Steven. Ayahuasca Reader. Santa Fe: Synergetic Press, 2000. p. 83-86.

TASTEVIN, Constantin. Le fleuve Murú. La Geographie: XLIIIe, 1925. p. 403-422.

TOWNSLEY, Graham. Song paths: the ways and means of yaminahua shamanic knowledge. L'Homme. Avril-Décembre, XXXIII Année, n. 126128, p. 449-468, 1993.

VIVEIROS DE CASTRO, Eduardo. Relatório de trabalho de campo. Brasília: Fundação Nacional do Índio, 1978.

. Os pronomes cosmológicos e o perspectivismo ameríndio. Mana, Rio de Janeiro, v. 2, n. 2, p. 115-144, 1996.

WEBER, Ingrid. Um copo de cultura: os Huni Kuin (Kaxinawa) do rio Humaita e a escola. Rio Branco: Editora da Universidade Federal do Acre, 2006.

WRIGHT, Robin. Profetas do Parika e do Càpi. In: LABATE, Beatriz Caiuby; GOULART, Sandra. O uso ritual das plantas de poder. Campinas:

Mercado de Letras-FAPESP, 2005. p. 83-115.

Recebido em 1\%/08/2014

Aceito em 08/09/2014 